\title{
Diagnostic Analysis and Modelling of Air Quality for Medium Sized City
}

\author{
Dr. Nitin W. Ingole ${ }^{1}$, Sachin V. Dharpal ${ }^{2 *}$
}

1. Prof and Dean (R\&D), Department of Civil Engineering, Prof Ram Meghe Institute of Technology \& Research, Badnera (Amravati), Maharashtra-444701, India.

2*. Research Scholar, Department of Civil Engineering, Prof Ram Meghe Institute of Technology \& Research, Badnera (Amravati), Maharashtra-444701, India.

*Corresponding author E-mail: dharpal007sv@gmail.com

Contributing Author E-mail: nwingole@mitra.ac.in

\begin{abstract}
It is witnessed that air pollution is an important issue regarding not only for human health but also for plants, animals and building materials. Increase in industrialisation, abundant use of automobiles, and network of highways, the quality of air of Amravati city is degrading day by day. The data has been collected for a period ranging from March 2020 to February 2021 for analysis and pollution forecasting model work. The concentration of Suspended Particulate Matter (SPM), Respiratory Suspended Particulate Matter (RSPM), Sulphur dioxide $\left(\mathrm{SO}_{2}\right)$, Nitrogen dioxide $\left(\mathrm{NO}_{2}\right)$ and Ozone $\left(\mathrm{O}_{3}\right)$ have been monitored over successive periods of time and also data is collected from monitoring stations controlled by MPCB. Numerous studies have been proposed for predicting pollution concentrations and improvement of performance of predictable models is an important issue. As is well known, collaborative observations proved that it can improve predictive performance. In this study, multivariate linear regression approach-based model was constructed to predict the RSPM in the air using the meteorological (air temperature, relative humidity, wind speed, rainfall) and air quality monitoring data (SPM, $\mathrm{NO}_{2}, \mathrm{SO}_{2}, \mathrm{O}_{3}$ ). Correlation between measured and model predicted vales of RSPM were 0.717,0.691,0.64 and 0.60 for winter, summer, monsoon and annual seasons respectively. However, the regression model based on seasonal data for winter was found to be more effective.
\end{abstract}

Key words - Air pollution, AQI, Multivariate Linear Regression Model, Pollution forecasting, NAAQS. 


\section{Introduction}

Air is a necessary requirement for survival and development of all lives on the earth. It affects health and influences the development of economy [1]. Today, due to expantion of urbanization and industrialization, the quality of air of every city is degrading day by day, with increasingly serious air pollution. The relationship between the air pollution and the mortality is well known since early days [2-4]. There are many pollutants in the atmosphere, such as $\mathrm{PM} 2.5, \mathrm{PM}_{10}, \mathrm{SO}_{2}, \mathrm{NO}, \mathrm{NO}_{2}, \mathrm{CO}, \mathrm{CO}_{2}, \mathrm{NOx}$ etc. Air pollution implies the presence in the outdoor atmosphere of one or more contaminants, such as dust, fumes, gas, mist, odour, smoke, or vapours, in quantities, with characteristics, and of duration such as to be injurious to human health, plant, or other creature life or to property, or which unreasonably interfere with the comfortable enjoyment of life and property [5-6]. Air pollution is the fifth leading cause of mortality worldwide, which causes seven million deaths per year and $88 \%$ of these deaths occur in developing nations. In a large city like Delhi about 1500 premature deaths are attributed to air pollution every year. The data received from WHO shows that almost the entire population of the world (99\%) breathe air that exceed guideline limits containing high level of pollution with low- income and middle-income countries suffering from very high exposures.

The occurrence of air pollution was not perceived as a major problem in most countries until the late 1950's and 1960's. It was hence considered a local problem in urban and industrial areas. Only after 1960's the air pollution evolved as a problem of regional and global dimension. The place from where air pollutants emit are both natural and manmade. Pollution problem arises not because of the magnitude of the anthropogenic emissions but also because of this emission get concentrated in the areas where people live and work. The appearance of mechanical and logical developments in different fields and assorted exercises of human race for its complexity have put additional heap on the air by method of releasing air pollutants. The environmental regulatory authorities [7] had prescribed the guidelines for the maximum permissible levels of various air pollutants, such as $\mathrm{SO}_{2}\left(80 \mu \mathrm{gm}^{-3}\right), \mathrm{NO}_{2}\left(80 \mu \mathrm{gm}^{-3}\right)$, and RSPM $\left(100 \mu \mathrm{gm}^{-3}\right)$, respectively.

In recent years, several research efforts had been made to develop the air quality prediction models. Atmospheric dispersion models used to predict the ground level concentration of the air pollutants around the sources [8-11] require precise knowledge of several source parameters and the meteorological conditions [12]. The statistical models endeavour to 
decide the hidden connection between a lot of information and targets. Several linear such as partial-least squares regression, multiple linear regression, principal component regression and nonlinear such as artificial neural networks, multivariate polynomial regression, support vector machines regression models are now available, which are capable of flexible input and output variables. Even though, linear regression modelling finds some applications in prediction of air quality [13-14], but it normally does not permit for consideration of nonlinearity and complex data [15].

Amravati city is a rapidly evolving city, with rural population around the city moving towards it. Due to the availability of resources such as education, market, business, health, and entertainment in the city there is increase in traffic conjunction on a regular basis. In addition to this five-star MIDC at Nandgaon Peth, that is located $20 \mathrm{~km}$ from the city centre is growing exponentially. It is noticed that the air quality of the city detracts from the daily routine that affects health of the people in the city and surrounded areas. The Sofia thermal power station contributes a large quantity of SPM, RSPM, SOx, NOx etc. [16]. A lot of research is being focussed on air pollutant emissions in Indian urban cities and industrial clusters. Also, there is a lack of adequate research on the extent of pollution concentrations in medium-sized cities, which are likely to expand in the near future. This further gives an opportunity to evaluate the strategies to reduce emissions from such sources [17]. Times of India in 2019 reported that Maharashtra, with 17 cities, tops the Environment Ministry's list of 102 non- attainment cities, where pollution levels are not meeting the set of standards. In Vidarbha Nagpur, Akola, Amravati and Chandrapur are the most polluted cities observed. The National Clean Air programme, which was launched by the ministry, states these cities have to mandatorily submit city specific action plans to combat air pollution.

In this work, we thrive towards diagnostic analysis of local air quality of Amravati city and a deeper understanding of air pollution using statistical methods. Multivariate linear regression model has been used for the prediction of RSPM for statistics analysis and then fitting results of the model were obtained for the one-year data, considering the different seasons. Inevitably, we intend to give direction to policymakers, on the most proficient method to diminish contamination presentation and consequently give health advantages to city tenants. 


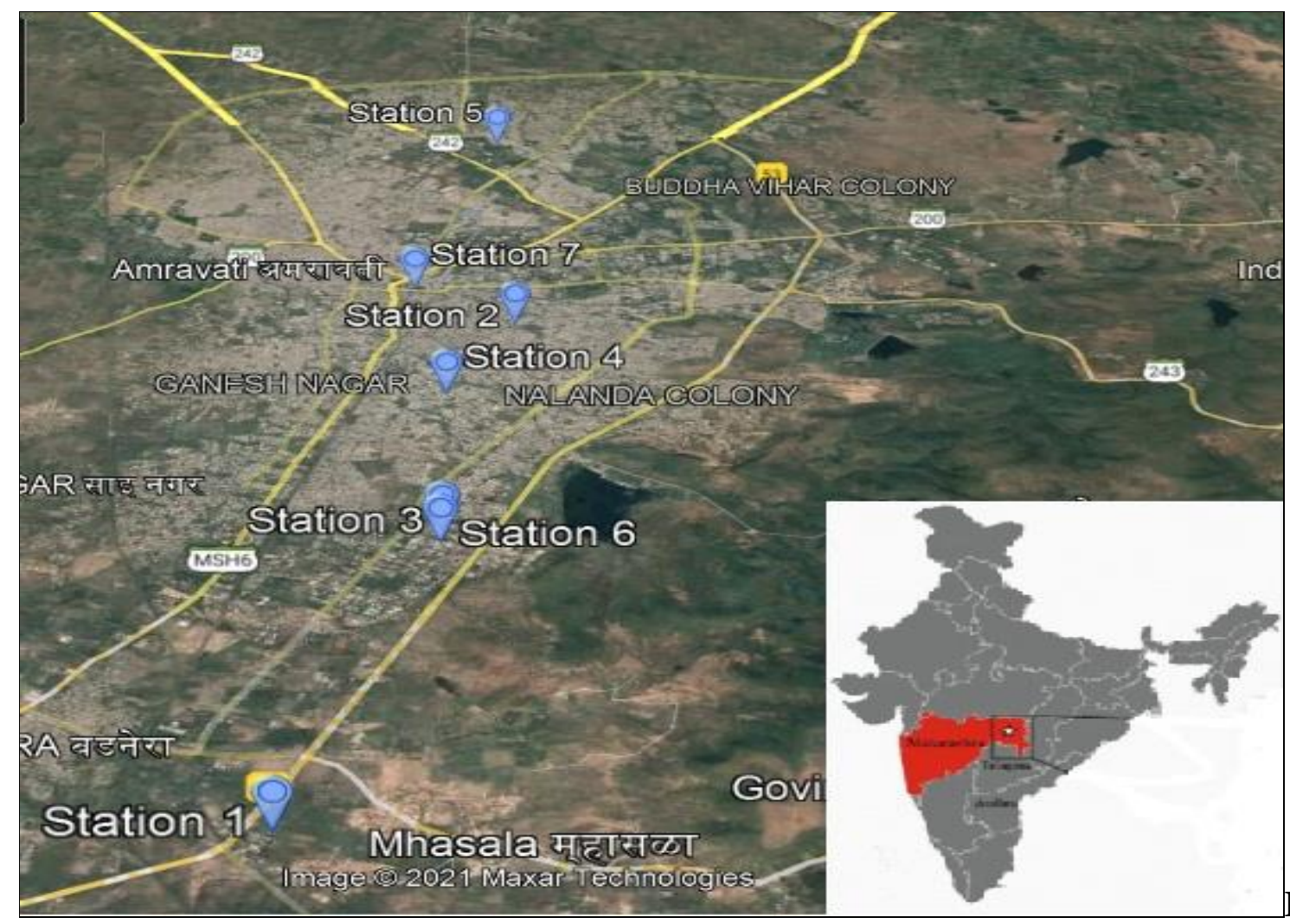

Fig. 1

Map showing the air quality monitoring locations in Amravati City

\section{Materials and Methods}

\subsection{The study area and data set}

The dataset considered in this study represents the air quality of Amravati city (India). Amravati city is situated in state of Maharashtra, India. It is the second largest city in Vidarbha region of Maharashtra after Nagpur and is administrative headquarter of Amravati district. Coordinates are $20^{\circ} 55^{\prime} 33^{\prime \prime} \mathrm{N} 77^{\circ} 45^{\prime} 53^{\prime \prime} \mathrm{E}$. According to the recent census (Census, 2011), the geographical area and population of the city are about $97.2 \mathrm{~km}^{2}$ and 646801, respectively. Amravati has a wet and dry climate with hot, dry summers and mild to cool winters. Summer season is from March to June, the rainy season is from July to October and the winter is from November to March. The highest and lowest temperatures ever recorded were $49.1^{\circ} \mathrm{C}$ on 25 May 2013 and $5.0^{\circ} \mathrm{C}$ on 9 February 1887 respectively. The annual average temperature of the city is $26.7^{\circ} \mathrm{C} \mid 80.0^{\circ} \mathrm{F}$. The annual rainfall is $1052 \mathrm{~mm} \mid$ 41.4inch, overall average temperature of Amravati city has shown tin figure 2. The average wind speed hence is $2.9 \mathrm{~m} / \mathrm{s}$ with the maximum wind speed of about $9 \mathrm{~m} / \mathrm{s}$. The average relative humidity remains around $57.8 \%$, varies from $14.2 \%$ to $98.1 \%$. The station pressure varies from $963 \mathrm{hPa}$ to $950 \mathrm{hPa}$, averaged around $975 \mathrm{hPa}$. Windrose of Amravati shows that 
predominantly wind blow from the WNW - about $17.12 \%$ of all wind directions shown in fig.3.
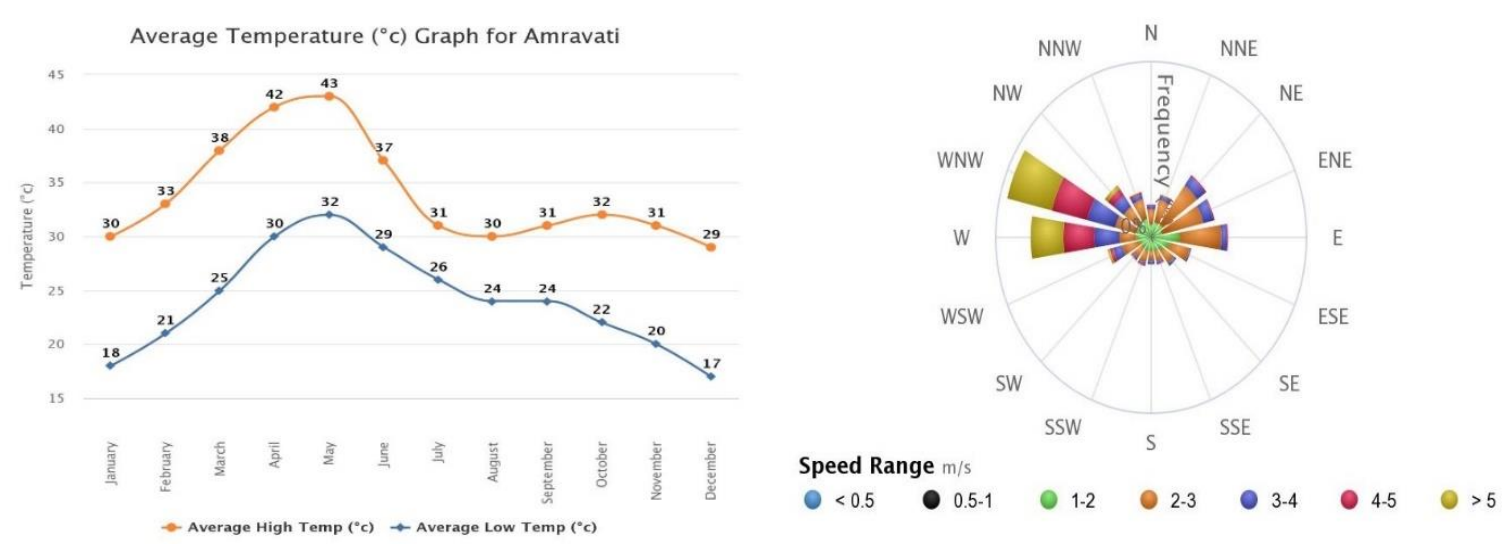

Fig 2.Overall Average temperature of Amravati city Fig 3.Average wind rose diagram of Amravati city

Table 1 Meteorological data summary

\begin{tabular}{|c|l|c|c|c|}
\hline Sr. No. & \multicolumn{1}{|c|}{ Parameter } & Minimum & Maximum & Average \\
\hline 1 & Wind Speed $\mathrm{m} / \mathrm{s}$ & 1 & 8.5 & 2.9 \\
\hline 2 & Temperature $^{\circ} \mathrm{C}$ & 10.5 & 44.2 & 26.9 \\
\hline 3 & Dew Point & \\
\end{tabular}

The values of meteorological parameters of Amravati city have been shown in Table 1. For present study, the data is collected for period ranging from march 2020 to February 2021 for analysis and pollution forecasting work. According to the database, the air pollution monitoring is performed for the periods of 24 hours ( 4 hour samples for gaseous pollutants and 8 hours samples for particulate matter) with a frequency of twice a week at all the four locations, namely PRMIT \& R, Badnera (S-1), and Rukmini Nagar (S-2), Renuka industries, MIDC(S-3), Venkatesh Colony(4), and some data is collected from three monitoring stations controlled by MPCB website ( http://www.mpcb.gov.in) such as Govt. Engg. College (S-5), MIDC (S-6) and Raj Kamal Square (S-7), in Amravati city. Concerning the impact of weather conditions on the pollutant levels, the meteorological parameters, such as the air temperature, $\mathrm{T}\left({ }^{\circ} \mathrm{C}\right)$, relative humidity, $\mathrm{RH}(\%)$, rainfall, $\mathrm{RL}(\mathrm{mm})$, and wind speed, WS $(\mathrm{km}$ $\mathrm{h}^{-1}$ ) values recorded at the meteorological stations, Amravati, were collected to assess their impact on the levels of the monitored air pollutants. The characteristic information of the five 
different air quality monitoring stations and the meteorological station are shown in Table 2 . All of these seven monitoring stations are located in areas where there is in mixed-use residential and commercial activities. The prevalence of air pollution in those areas are largely due to residential and automobile activity.

Table 2 Sampling Stations

\begin{tabular}{|l|l|l|l|}
\hline Stations & Location & Type of area & Data Collection \\
\hline $\mathrm{S}-1$ & PRMIT \& R, Badnera & Institutional & Self-Monitored \\
\hline $\mathrm{S}-2$ & Rukmini Nagar, Amravati & Commercial & Self-Monitored \\
\hline $\mathrm{S}-3$ & Renuka Industries, MIDC Amravati & Industrial & Self-Monitored \\
\hline $\mathrm{S}-4$ & Venkatesh Colony, Farshi Stop, Amravati & Residential & Self-Monitored \\
\hline $\mathrm{S}-5$ & Govt. College of Engineering Amravati & Residential & MPCB Website \\
\hline $\mathrm{S}-6$ & A-23 MIDC, Amravati & Industrial & MPCB Website \\
\hline $\mathrm{S}-7$ & Vanita Samaj, Rajkamal Square, Amravati & Commercial & MPCB Website \\
\hline
\end{tabular}

\subsection{Methodology}

Analysis of Suspended Particulate Matter SPM was carried out using High Volume Sampler (PEM - HVS-8) at an average flow rate of 1.0-1.5 $\mathrm{m}^{3} / \mathrm{min}$ at two sampling stations (details given in Table 2) on daily basis during the study period. The dust comprising of the suspended particulate matter is collected on a pre weighed Whatman glass microfibre filter paper (GF/A $20.3 \times 25.4 \mathrm{~cm}$ ). The Sampler is fixed at a breathing height of $1.5 \mathrm{~m}$ above the ground level and flow rate is noted after 5 minutes of starting of the sampling. The concentration of the particulate matter is estimated on the net mass collected divided by the volume of air sampled. For collection of RSPM dust sampler has been used. For the collection of gaseous pollutants, like $\mathrm{SO}_{2}$ and $\mathrm{NO}_{x}$, the $\mathrm{O}_{3}$ sampler having thermoelectrically cooled gaseous attachment containing impingers (bubbler trains) in series with following reagents, were used for collection shown in table 3. The collected samples were put in ice boxes immediately after sampling and kept in a refrigerator prior to analysis. The samples were analysed spectrophotometrically (UV-Visible Spectrophotometer 118) using West and Gaeke method, Jacob and Hocheiser modified method and chemical method for analysis of $\mathrm{SO}_{2}, \mathrm{NO}_{2}$ and $\mathrm{O}_{3}$ respectively. 
Table 3 Gaseous pollutants, Particulate Matter and their absorbing reagents/ Filter papers

\begin{tabular}{|c|c|c|}
\hline Sr No. & Pollutant & Absorbing reagents \& Filter papers \\
\hline 1 & $\mathrm{SO}_{2}$ & Tetra chloromercurate \\
\hline 2 & $\mathrm{NO}_{2}$ & Alkali- Arsanite \\
\hline 3 & $\mathrm{O}_{3}$ & Potassium iodide \\
\hline 4 & $\mathrm{SPM}$ & Whatman glass microfiber filter paper \\
\hline 5 & $\mathrm{RSPM}$ & Whatman glass microfiber filter paper \\
\hline
\end{tabular}

\subsection{Air Quality Index (AQI)}

Air Quality Index is defined as a scheme that transforms the (weighted) values of individual pollution related parameter into single number or set of numbers [18-19]. It is a comprehensive assessment of air quality concentration of criteria pollutants namely Respirable Suspended Particulate Matter (RSPM), Sulphur dioxide $\left(\mathrm{SO}_{2}\right)$, Nitrogen dioxide $\left(\mathrm{NO}_{2}\right)$, Ozone $\left(\mathrm{O}_{3}\right)$ and Suspended Particulate Matter (SPM). An air quality index (AQI) is a number used by the government agencies to communicate with public how much pollution is there currently or how predictable it is. As the Air Quality Index increases, an increasingly large percentage of the population is likely to experience increasingly serious health consequences. The concentration of each pollutant in the air is measured hourly and converted into a number starting from zero in ascending order via a standard index or scale. The calculated numbers of each pollutant are known as a sub-index. The highest sub-index for any given hour is recorded as the AQI for that hour. In simple terms, AQI similar to touchstone ranging from zero to five hundred (0-500). The index is a relative measure, that is when the index is low, the quality of air is better and the lesser the health concern, and vice versa. The concentration of each pollutant varies, therefore, AQI values are grouped into ranges assigned to a standardized public health warnings and colour code.

AQI is calculated by a linear function, by determining the awareness of the pollutants. The equation [20] below is used to compute AQI.

$$
I=\frac{I_{\text {high }}-I_{\text {low }}}{C_{\text {high }}-C_{\text {low }}}\left(C-C_{\text {low }}\right)+I_{\text {low }}
$$

Where,

$\mathrm{I}=$ the (Air Quality) index, 
$\mathrm{C}=$ the pollutant concentration,

$\mathrm{C}_{\{\text {low }}=$ the concentration breakpoint that is $\leq \mathrm{C}$,

$\mathrm{C}_{\{\text {high }\}}=$ the concentration breakpoint that is $\geq \mathrm{C}$,

$\mathrm{I}_{\{\text {low }\}}=$ the index breakpoint corresponding to $\mathrm{C}_{\{\text {low }\}}$,

$\mathrm{I}_{\{\text {high }\}}=$ the index breakpoint corresponding to $\mathrm{C}_{\{\text {high }\}}$.

Table 4 Health Impacts based on AQI

\begin{tabular}{|l|l|}
\hline \multicolumn{1}{|c|}{ AQI } & \multicolumn{1}{c|}{ Associated Health Impacts } \\
\hline Good (0-50) & Minimal impact \\
\hline Satisfactory (51- & May cause minor breathing discomfort to sensitive people. \\
\hline Moderate (101-200) & $\begin{array}{l}\text { May cause breathing discomfort to people with lung disease such } \\
\text { as asthma, and discomfort to people with heart disease, children } \\
\text { and older adults. }\end{array}$ \\
\hline Poor (201-300) & $\begin{array}{l}\text { May cause breathing discomfort to people on prolonged } \\
\text { exposure, and discomfort to people with heart disease. }\end{array}$ \\
\hline Very poor (301- & $\begin{array}{l}\text { May cause respiratory illness to the people on prolonged } \\
\text { exposure. Effect may be more pronounced in people with lung }\end{array}$ \\
\hline Severe (401-500) & $\begin{array}{l}\text { May cause respiratory impact even on healthy people, and } \\
\text { serious health impacts on people with lung/heart disease. The } \\
\text { health impacts may be experienced even during light physical }\end{array}$ \\
\hline
\end{tabular}

\subsection{Predictive modelling approach}

Here, we select multivariable linear regression model (MLR) for predicting urban air quality [1][21]. Using a set of seven independent variables in Amravati city (Maharashtra, India) pertaining to air quality and meteorological parameters as the estimators.

Multiple linear regressions, also called simply as multiple regression, is a mathematical method that uses various descriptive variables in order to predict the outcome of response variable. Multiple regressions are an extension of linear regression which utilises just one explanatory variable. Multivariable regression models are utilising to establish the relationship between a dependent variable and more than one independent variable. Multivariable regression can be used for a variety of various purposes in research works. 
Multivariate regression emerges when it has more than one independent variable, and simple linear regression is inoperative. Real-world data includes many variables or features and if there is availability in the data, we may need multivariate regression for improved analysis. Therefore, the suppositions are: linearity; normality; independence; homoscedasticity. Or else we may say that, the residuals of a good model should be distributed regularly and randomly i.e. the unknown does not depend on X ("homoscedasticity").

The linear regression equation shown in the form,

$Y=a+b X$,

where $\mathrm{X}$ is the explanatory variable and $\mathrm{Y}$ is the dependent variable. The slope of the line is $\mathrm{b}$, and $\mathrm{a}$ is the $\mathrm{Y}$ intercept (the value of $\mathrm{y}$ when $\mathrm{x}=0$ ).

The multiple linear regression equation is as follows [21,22]:

$$
y=b_{0}+b_{1} X_{1}+b_{2} X_{2}+\ldots .+b_{p} X_{p}+\mathrm{e}
$$

Where, $\mathbf{y}=$ the predicted value of the dependent variable, $\mathbf{b}_{\mathbf{0}}=$ the $\mathrm{y}$-intercept (value of $\mathbf{y}$ when all other parameters are set to 0$), \mathbf{b}_{1} \mathbf{X}_{1}=$ the regression coefficient $\left(B_{1}\right)$ of the first independent variable $\left(\mathbf{X}_{1}\right)$ (a.k.a. the effect that increasing the value of the independent variable has on the predicted $\mathbf{y}$ value), $\ldots=$ do the same for however many independent variables you are testing, $\mathbf{b}_{\mathbf{n}} \mathbf{X}_{\mathbf{n}}=$ the regression coefficient of the last independent variable, $\mathbf{e}=$ model error (a.k.a. how much variation there is in our estimate of $\mathbf{y}$ ). Each regression coefficient represents the change in $\mathrm{Y}$ relative to the change of one unit of successive independent variable. In case of multiple regression, for example, b1, it is a change in $\mathrm{Y}$ relation to a single unit change in $\mathrm{X}_{1}$, holding all the other independent variables invariably. Also, statistical tests can be performed to test whether each regression coefficient is significantly different from zero. After modification of equation, a generic model was provided as follows-

$\mathrm{RSPM}=\left(\alpha+\varepsilon_{1}\right)+\left(\beta_{1}+\varepsilon_{2}\right) \times \mathrm{SO}_{2} \times\left(\beta_{2}+\varepsilon_{3}\right)+\mathrm{NO}_{2} \times\left(\beta_{3}+\varepsilon_{4}\right)+\mathrm{O}_{3} \times\left(\beta_{4}+\varepsilon_{5}\right)+\mathrm{SPM} \times$ $\left(\beta_{5}+\varepsilon_{6}\right)+\mathrm{RH}\left(\beta_{6}+\varepsilon_{7}\right)+\mathrm{WV}\left(\beta_{7}+\varepsilon_{8}\right)+\mathrm{RL}\left(\beta_{8}+\varepsilon_{9}\right)$

Where RSPM is its mass concentration at ground level $\left(\mu \mathrm{gm}^{-3}\right)$, TEMP is temperature $\left({ }^{\circ} \mathrm{C}\right)$, $\mathrm{RH}$ is relative humidity $(\%), \mathrm{WV}$ is wind velocity $(\mathrm{m} / \mathrm{s}), \mathrm{RL}$ is rainfall $(\mathrm{mm})$ and $\mathrm{SO}_{2}, \mathrm{NO}_{2}$, 
$\mathrm{O}_{3}$, SPM are the mass concentration of four pollutants at ground level, $\beta_{1}, \beta_{2}, \ldots \beta_{8}$ are the slopes corresponding to the respective variables; and $\left(\alpha+\varepsilon_{1}\right)$ is the intercept [23]. In addition to meteorological factors, there may be different degrees of correlation between RSPM and $\mathrm{SO}_{2}, \mathrm{NO}_{2}$. The concomitant variables of the model are the meteorological parameters (TEMP, RH, WV and RL) and Four types of pollution indices ( $\left.\mathrm{SO}_{2}, \mathrm{NO}_{2}, \mathrm{O}_{3}, \mathrm{SPM}\right)$.

Due to extreme weather and pandemic situation some data may have deficiencies in variables related to the proposed linear regression model e.g. missing of some data such as SPM, RSPM, $\mathrm{SO}_{2}, \mathrm{NO}_{2}, \mathrm{O}_{3}$ etc. After Compilation and screening the complete data sets are divided into different seasons such as annual, summer, winter and monsoon and consists of different samples and eight variables as shown in table 6.

\section{Results \& Discussion}

\subsection{Results and Discussion for Diagnostic analysis}

According to monthly and also location wise observations of ambient air quality parameters, e.g. SPM, RSPM, $\mathrm{SO}_{2}, \mathrm{NO}_{2}$ and $\mathrm{O}_{3}$ for the entire study period are graphically denoted in Fig. 4 to Fig. 8. The computed values of AQI for different stations are represented in Fig. 9.

During the study period SPM was found maximum at Station -2 \& Station- 3 i.e. Rukmini Nagar and Near Renuka Industries, MIDC. The highest $237.085\left(\mu \mathrm{g} / \mathrm{m}^{3}\right)$ and lowest 63.53 $\left(\mu \mathrm{g} / \mathrm{m}^{3}\right)$ values of SPM were recorded at Stations-3 in January 2021 and at station-4 in June 2020 respectively. Average SPM values at stations 2 and 3 exceed the prescribed limit of National Ambient Air Quality Standard (NAAQS) set by the CPCB but it was slightly away from limit boundary because of less vehicular traffic during pandemic situation of Covid-19. 'Rukmini Nagar', the first locality of new Amravati i.e. extension of Amravati, just in front of central bus station, so many educational institutions, water treatment plant with their offices. There are so many renounced hospitals in the area, so many business complexes, railway station is adjacent to it, becoming commercial area in addition to the main commercial area of the city very nearer to it. So many government offices and also offices of private firms are situated in that area. Because of this congestion naturally it is adding to the pollution of the area. At second instance 'MIDC Area', we are having so many small-scale industries in MIDC area, Amravati. MIDC situated between mini bypass (old) and express Highway (new), meaning thereby the traffic of national highway standard and city of corporation standard are again adding to pollution of the area. As Amravati is a fast- 
developing city, for residential purposes, administrative purposes, industrial purposes and for transport purposes e.g. highways, railways \& air strip etc. So, for construction purposes so many brick kills are coming up in the area. Owing to above reasons the air pollution of the area is fast increasing. SPM levels were relatively high during winter (November-February) in comparison to monsoon (July-October) and summer (March-June) in almost all the seven locations. This tendency was because in cold, anti-cyclonic condition prevailed which was characterised by very slow wind or calm, with slight dispersion or dilution of pollutants resulting in high level of SPM. As compared to above, the reading of the pollution taken in residential area of Amravati city, appears to be within permissible limit.

Similar SPM trend, RSPM also found maximum at 2 and 3. RSPM values were lowest in monsoon due to intermittent precipitation. The highest $(85 \mu \mathrm{g} / \mathrm{m} 3)$ and lowest $(42 \mu \mathrm{g} / \mathrm{m} 3)$ levels of RSPM were recorded at station-3 in March 2020 and at Station-6 in June 2020 respectively due to similar causes like SPM. When SPM level exceeds the prescribed limit, RSPM levels also then increases. It was observed thar the excess RSPM generation was also transport related and industrial cluster.

No significant $\mathrm{SO}_{2}$ detection was observed in all locations and values were significantly below the $\mathrm{CPCB}$ prescribed standards. It was noticed that $\mathrm{SO}_{2}$ concentration was significantly lower during monsoon period as compared to summer and winter. This was due to the occurrence of high-speed wind and frequent precipitations. Similarly, the detected concentration of $\mathrm{NO}_{2}$ and $\mathrm{O}_{3}$ were far below the prescribed limit set by the CPCB at all the locations. $\mathrm{NO}_{2}$ concentrations were found to be higher during the winter than in the summer. This is mainly because of burning of fuel(wood, oil, natural gas, coal) heating systems in winter months. As the weather warm up during the summer season, ground-level ozone pollution increases as pollutants react to heat and sunlight. Ozone levels often rise with summer wildfires, further boosting the air quality and ozone-related breathing issues.

\subsubsection{Determination of AQI}

The average AQI for different stations are represented in Figure-9. The highest (102) and lowest (18) AQI were observed at Station-6 and Station-4 respectively. It is seen that the AQI values in Station-2 and Station-3 were more than 100 indicating effect of the ambient air on old people and children. Moderate air pollution at Stations-2,5 and 7. Light air pollution is 
noticed at Stations- $1 \& 4$, out of which two locations are industrial sites. High values of AQI are mainly due to SPM and RSPM emission.

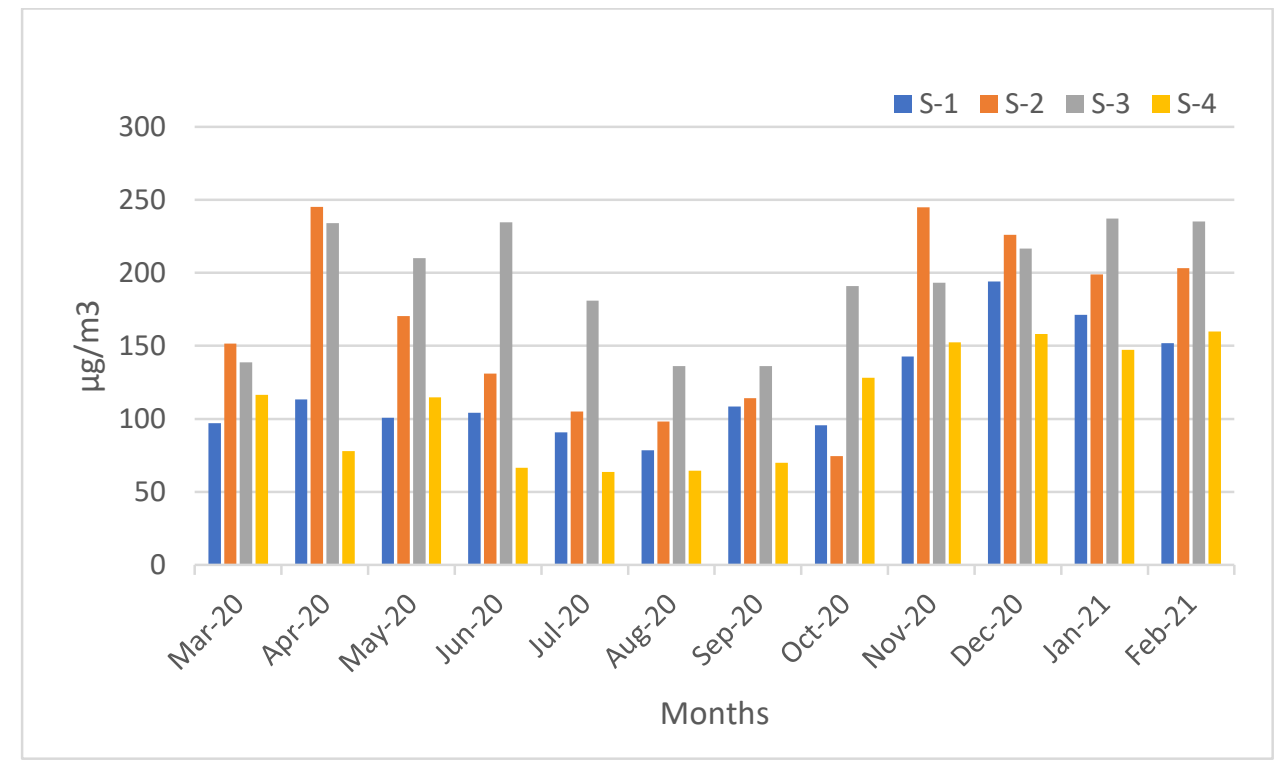

Fig. 4 Month wise variation in concentration of SPM

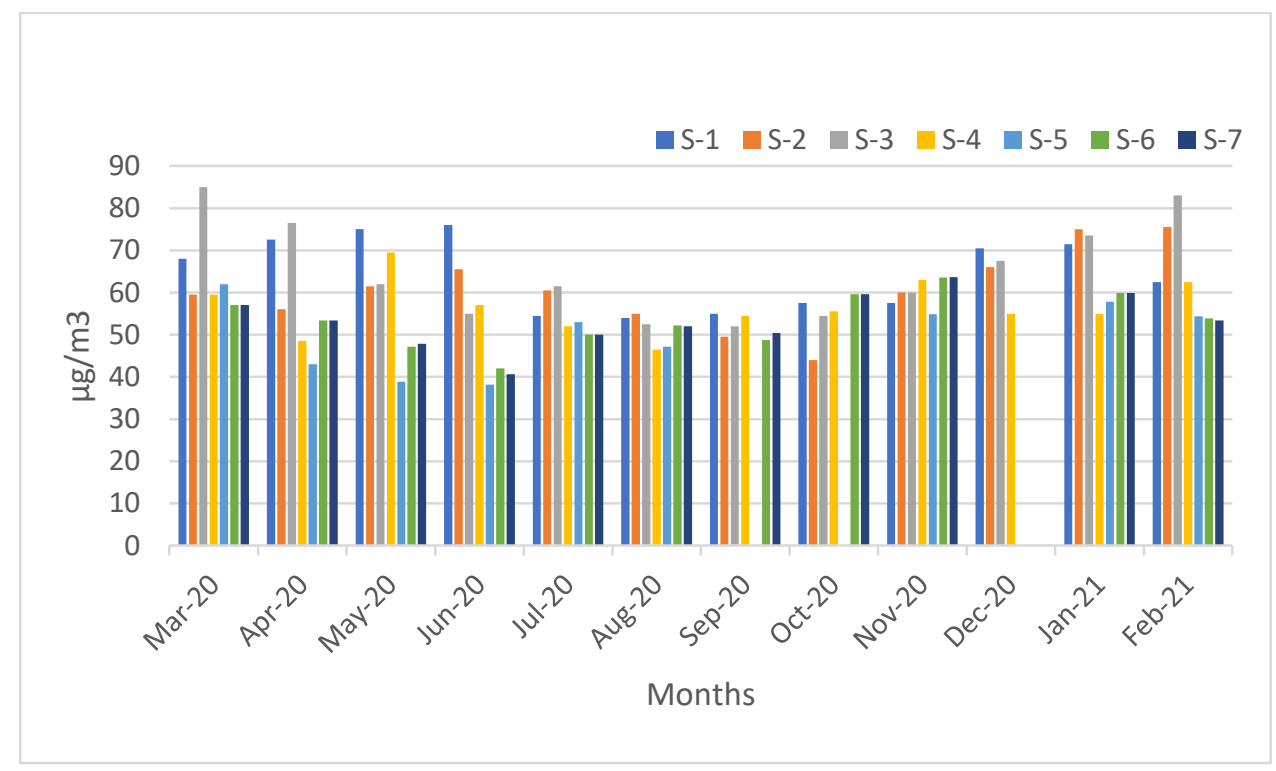

Fig. 5 Month wise variation in concentration of RSPM 


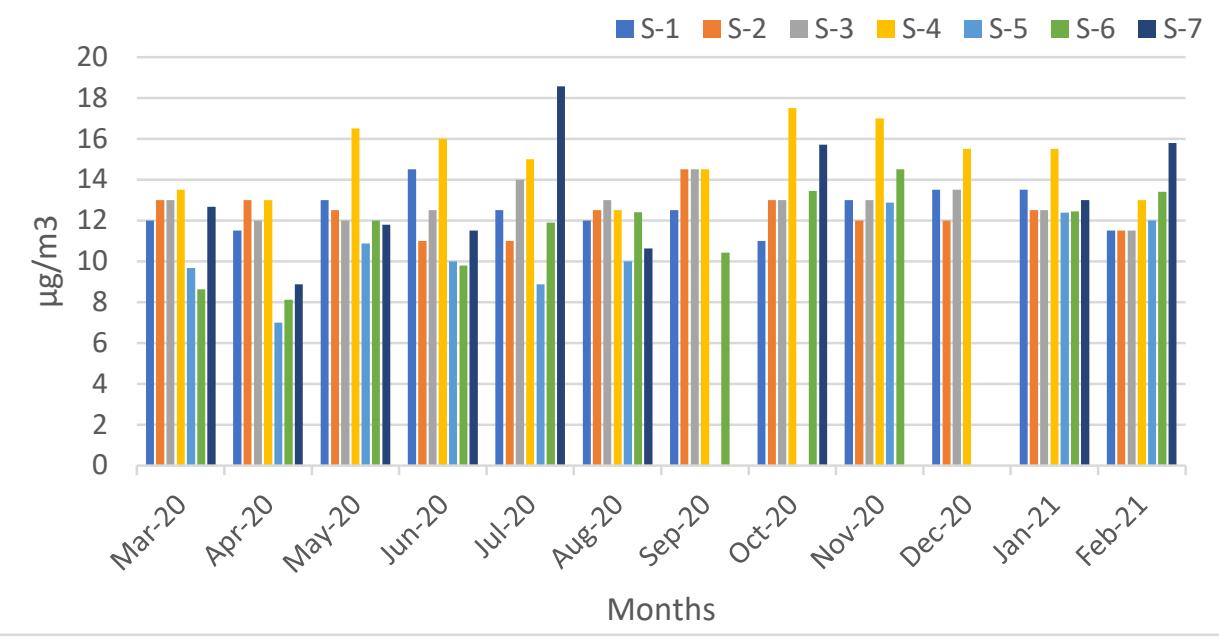

Fig. 6 Month wise variation in concentration of $\mathrm{SO}_{2}$

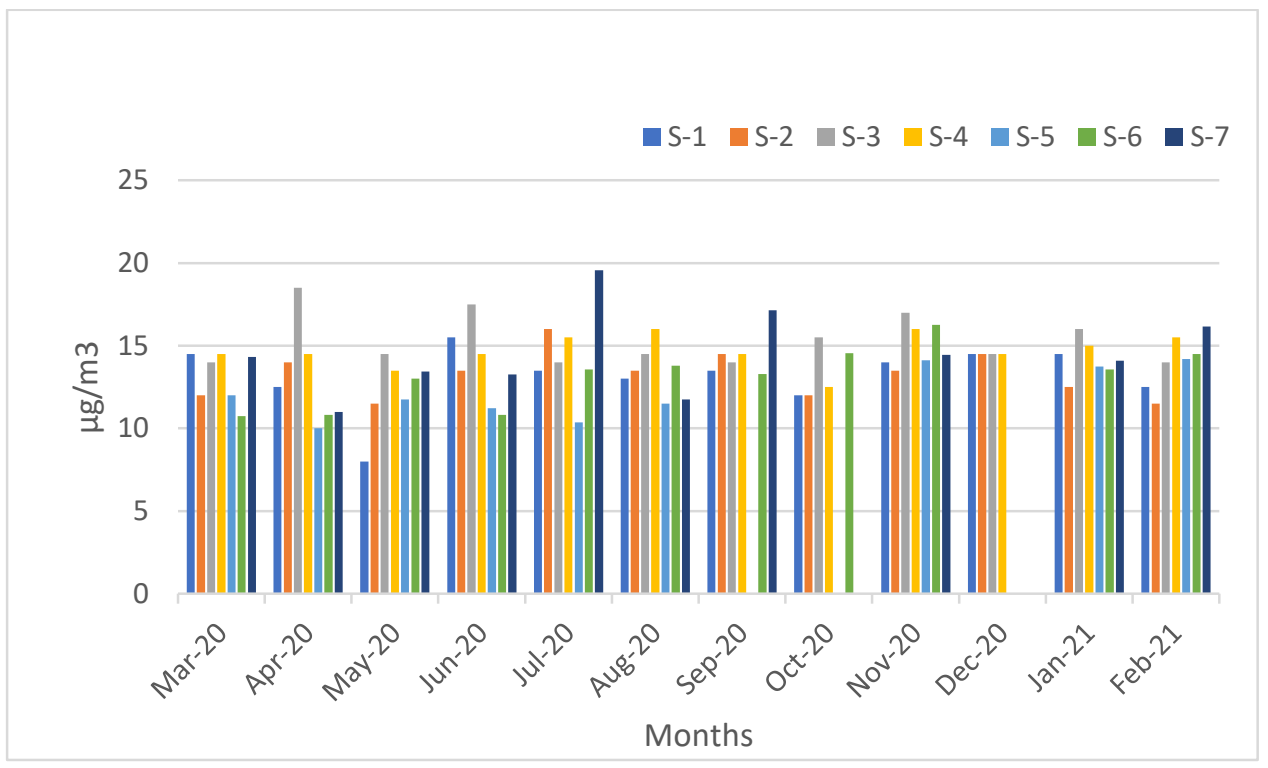

Fig. 7 Month wise variation in concentration of $\mathrm{NO}_{2}$ 


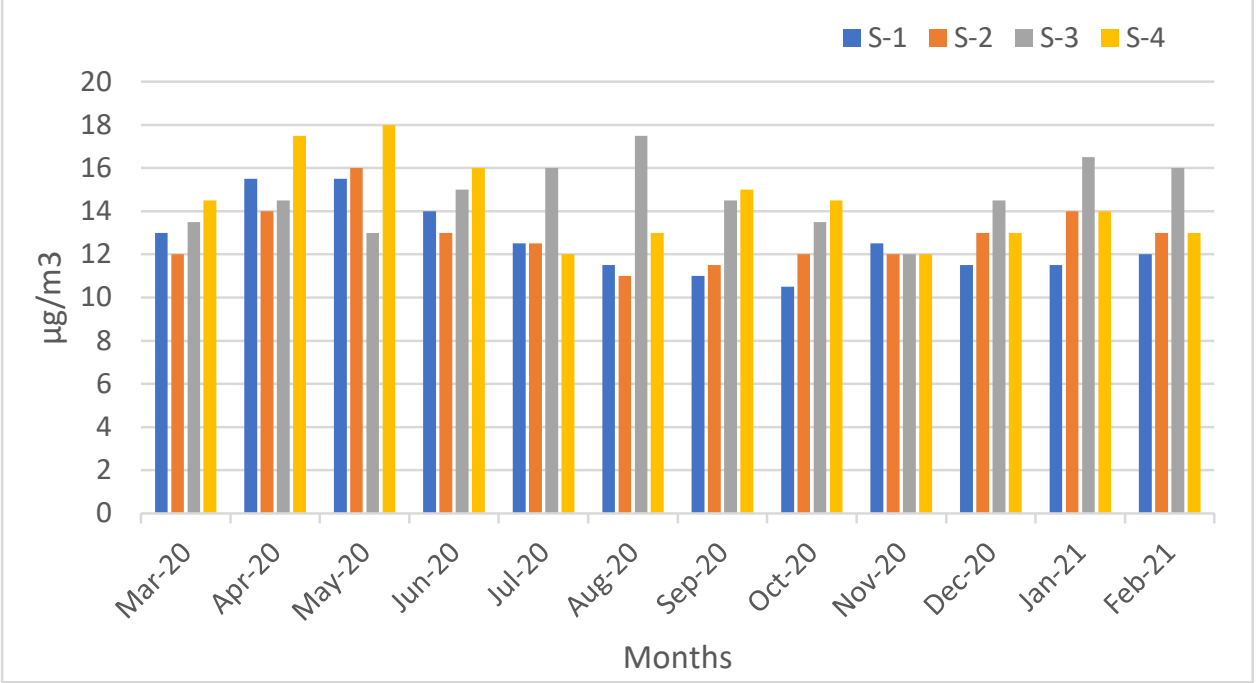

Fig. 8 Month wise variation in concentration of $\mathrm{O}_{3}$

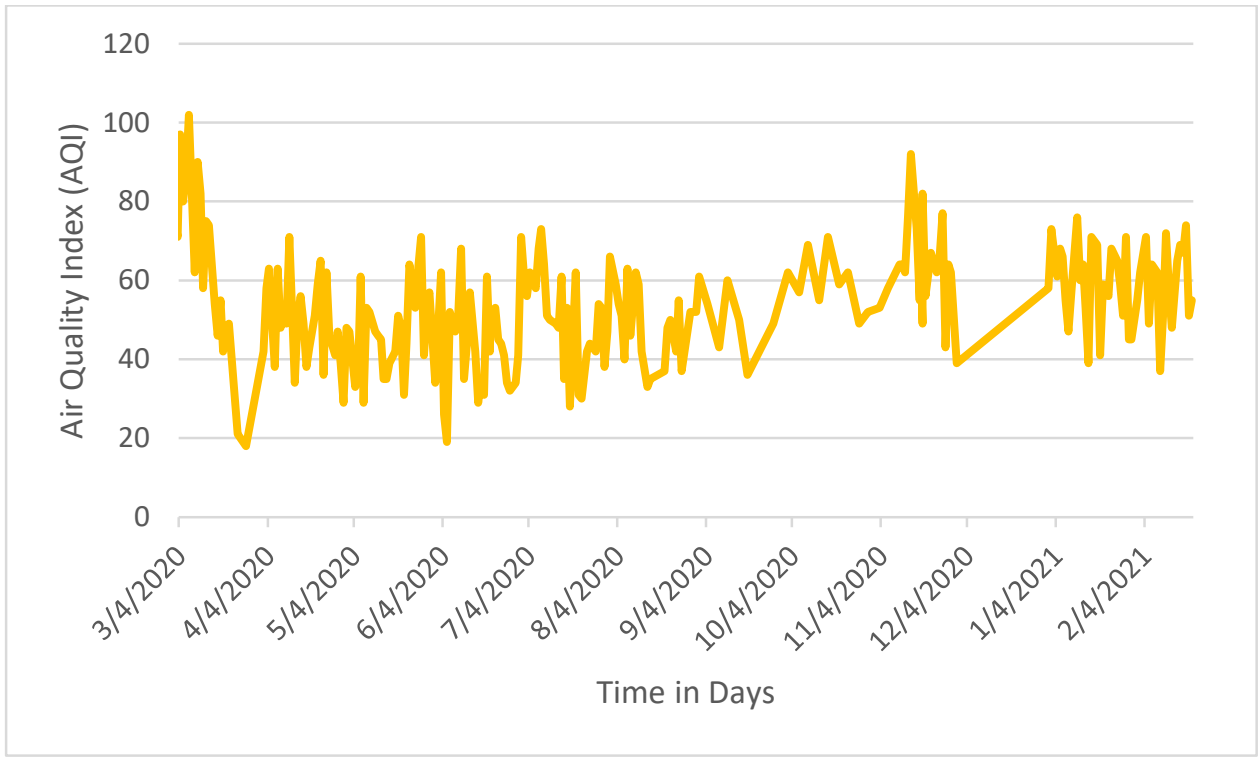

Fig. 9 Air Quality Index for March 2020 to February 2021

\subsection{Results and Discussion for Predictive Analysis}

\subsubsection{Regression results}

The study gives the regression result by using seasonal data of Amravati city. As the available data related to RSPM have expressed seasonal differences, they have been fitted for each season to examine their respective performance of regression. The different coefficients related to different regression models are shown in table 5. After the RSPM monitoring data were further grouped by three seasons (Summer: March-June; Winter: November-February 
and Monsoon: July-October), the seasonality of the data was apparent. As can be seen in table 5, the mean RSPM concentrations for winter exceeded those of summer and monsoon.

The scatter distribution for the fitting and cross validation of Amravati City RSPM data from March 2020 to February 2021 are shown in fig. 11 to 12 The fitted line is generated by using Excel software packaging, which is based upon method of least square to find out the linear trend with the best fitting among the scatter points. The $\mathrm{R}^{2}$ for the regression model of annual data(fig.11) was 0.6023. Similarly, the $\mathrm{R}^{2}$ for the regression model of winter(fig.12), monsoon(fig.13) and summer(fig.14) were $0.717,0.64$ and 0.691 respectively. It has been observed that in winter season the $\mathrm{R}^{2}$ of RSPM data was higher than among the other seasons. The reason would be that the mean and maximum RSPM concentrations in winter were the highest for the entire year. Meteorological conditions were stable during this period. This provides indirect evidence that the winter data could better predict RSPM concentrations during that period. During monsoon, the value of $\mathrm{R}^{2}$ regarding RSPM data is higher than the annual value. In summer the mean and maximum RSPM concentrations for monsoon were far lower than winter but higher than monsoon and annual. Summertime pollution often spikes due to arid weather loosening more dust in to the air. These particles can travel great distances and cross borders. Dry and dusty weather, combined with increase temperatures significantly increased the presence of air born RSPM pollution. This may due to the loose soil, air born ash, and stripped-up road dust.

Table 5 Descriptive and statistics and summary of regression results

\begin{tabular}{|c|c|c|c|c|c|c|c|}
\hline Seasonal RSPM & $\mathbf{N}$ & Min & Max & Mean & Median & SD & CV \\
\hline Annual & 329 & 18 & 103 & 53.6 & 53 & 14.28 & 26.646 \\
\hline Winter & 106 & 18 & 103 & 60.75 & 48 & 16.24 & 32.44 \\
\hline Summer & 129 & 37 & 92 & 51.75 & 62 & 10.89 & 17.923 \\
\hline Monsoon & 94 & 22 & 73 & 50.051 & 52 & 11.3 & 21.94 \\
\hline
\end{tabular}

\subsubsection{Correlation coefficients}

A correlation matrix between various air quality and meteorological parameters is presented in table 7. The magnitude of inter - correlations between the parameters suggests that the atmospheric pollution depends on different meteorological variables. Correlation is the mutual relationship between two variables. Direct correlation is said to exist when increase or 
decrease in the value of one parameter is associated with a corresponding increase or decrease in the value of the other. Correlation is considered positive when increase in one parameter causes increase in other parameter and is said negative when increase in one parameter causes decrease in the value of the other and vice versa. The correlation coefficient ranges between +1 and -1 . When it is in the range of +0.8 to 1.0 and -0.8 to -1.0 , the correlation is characterized as strong, is moderate in the range of +0.5 to +0.8 and -0.5 to 0.8. If the correlation ranges between -0.5 and +0.5 , it is characterized as weak [19]. The correlation coefficient value among the parameters is given in Table 7. It is seen that AQI is having strong as well as positive correlation with RSPM (0.9994). This indicates that RSPM concentrations squarely influence the value of AQI. The correlations of different air pollutants and meteorological variables somewhat differ in different related studies may be subjected to variations depending upon its location and its unique meteorological characteristics [1]. 
Table 6 The coefficients estimated in regression models

\begin{tabular}{|l|c|c|c|c|c|c|c|r|c|}
\hline Seasons & Constant & $\mathbf{S O}_{\mathbf{2}}$ & $\mathbf{N O}_{\mathbf{2}}$ & $\mathbf{O}_{\mathbf{3}}$ & \multicolumn{1}{|c|}{ SPM } & \multicolumn{1}{c|}{ TEMP } & RH & \multicolumn{1}{c|}{ WV } & RL \\
\hline Annual & -2.85031 & 1.448645 & 0.828062 & 0.710085 & 0.044149 & -0.03256 & 0.337263 & 2.130349 & -0.06033 \\
\hline Winter & 84.28984 & 2.395419 & 1.164329 & 0.645665 & 0.06644 & 5.64794 & -4.18643 & 0.00001 & 0.310424 \\
\hline Monsoon & 37.39943 & 0.755868 & 1.515882 & -1.68706 & 0.064109 & 0.00001 & 0.17522 & 2.013837 & -0.01959 \\
\hline Summer & 74.66649 & 2.744091 & -0.32069 & 1.026442 & -0.04915 & -2.33398 & -0.39217 & 0.00001 & 0.709683 \\
\hline
\end{tabular}

Table 7 Correlation coefficient values among the parameters

\begin{tabular}{|c|c|c|c|c|c|c|c|c|c|c|}
\hline & $\mathrm{SO}_{2}$ & $\mathrm{NO}_{2}$ & $\mathrm{O}_{3}$ & $S P M$ & $R S P M$ & $A Q I$ & TEMP & $R H$ & $W S$ & $R L$ \\
\hline $\mathrm{SO}_{2}$ & 1 & & & & & & & & & \\
\hline $\mathrm{NO}_{2}$ & 0.865851 & 1 & & & & & & & & \\
\hline $\mathrm{O}_{3}$ & 0.132695 & 0.129499 & 1 & & & & & & & \\
\hline SPM & 0.040729 & 0.091983 & 0.137069 & 1 & & & & & & \\
\hline RSPM & 0.505366 & 0.491735 & 0.190668 & 0.30582 & 1 & & & & & \\
\hline AQI & 0.57823 & 0.590594 & 0.237296 & 0.716915 & 0.999421 & 1 & & & & \\
\hline TEMP & 0.114765 & 0.105715 & -0.06845 & 0.100077 & 0.019026 & 0.054527 & 1 & & & \\
\hline $\mathrm{RH}$ & 0.230351 & 0.234066 & -0.17134 & -0.20719 & 0.074416 & 0.191565 & -0.09056 & 1 & & \\
\hline WS & -0.23109 & -0.23214 & 0.069217 & -0.25069 & -0.25044 & -0.33413 & 0.154853 & -0.71689 & 1 & \\
\hline $\mathrm{RL}$ & 0.043336 & 0.053991 & -0.16984 & -0.54794 & -0.19172 & -0.11608 & -0.08789 & 0.792385 & -0.23081 & 1 \\
\hline
\end{tabular}




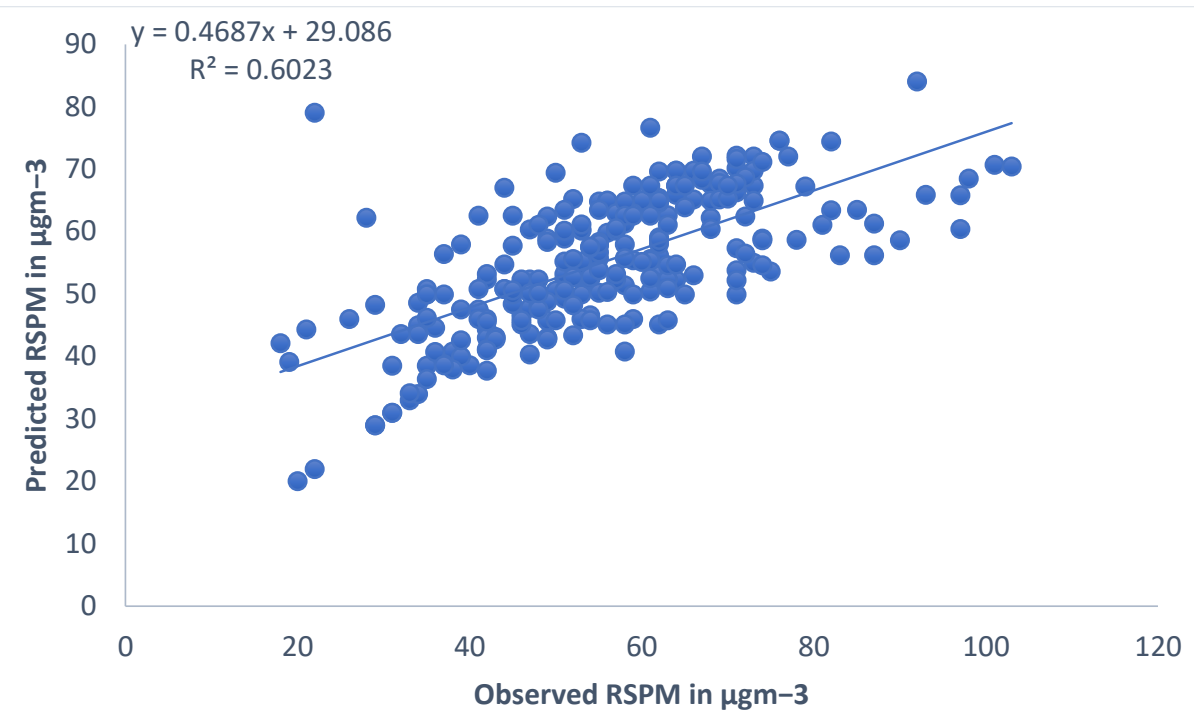

Fig. 10 Fitting results of annual RSPM data for March 2020 to February 2021

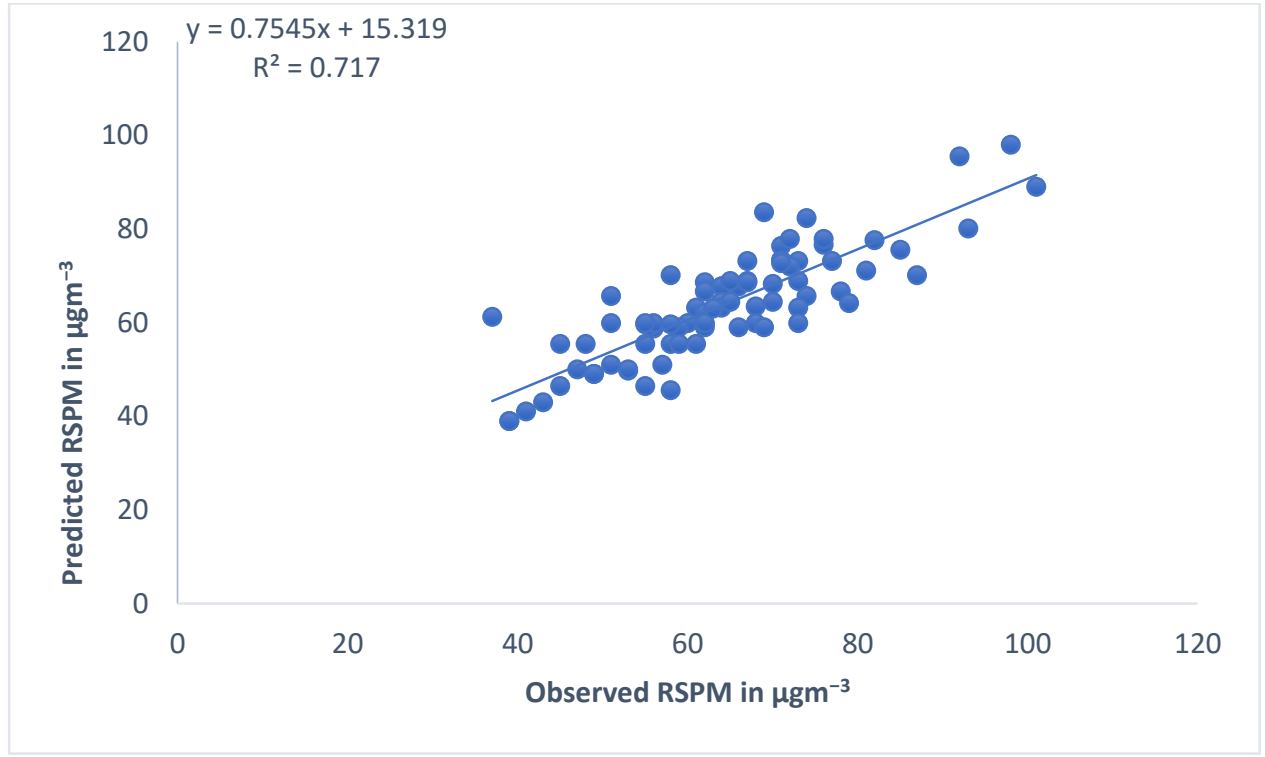

Fig. 11 Fitting results of winter RSPM data for March 2020 to February 2021 


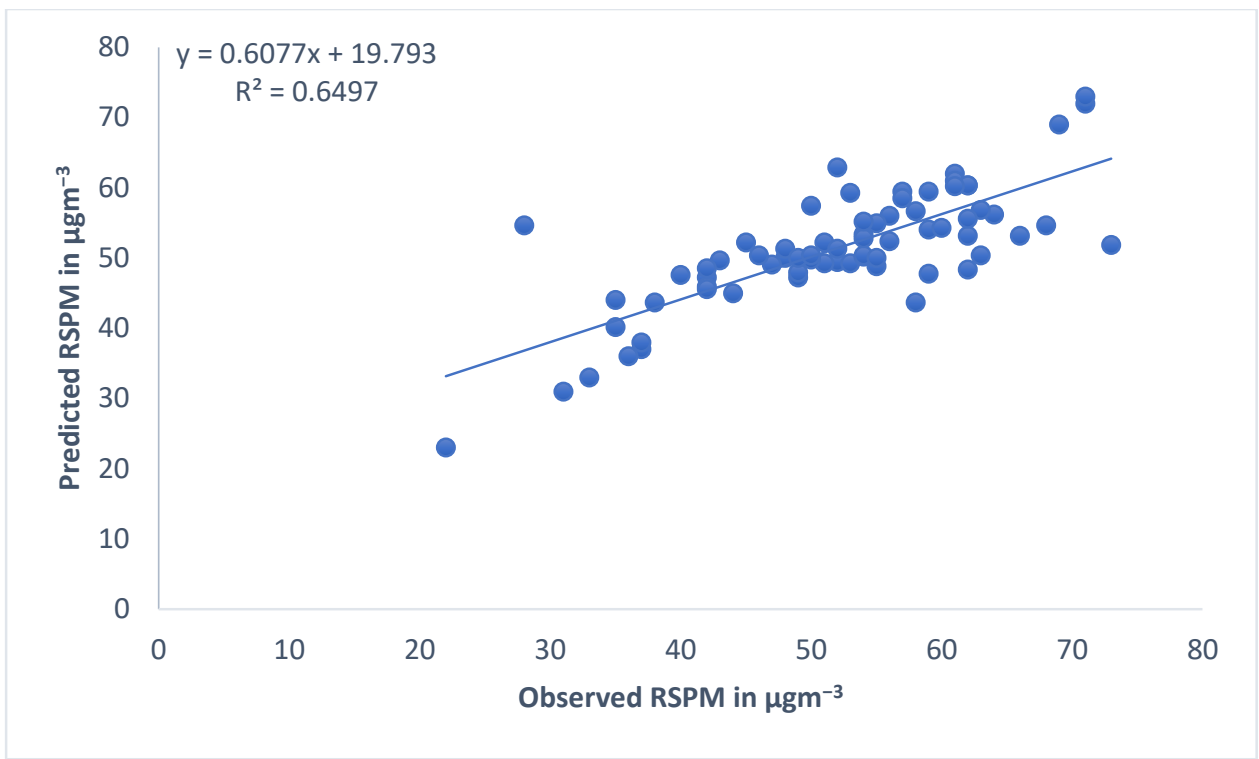

Fig. 12 Fitting results of monsoon RSPM data for March 2020 to February 2021

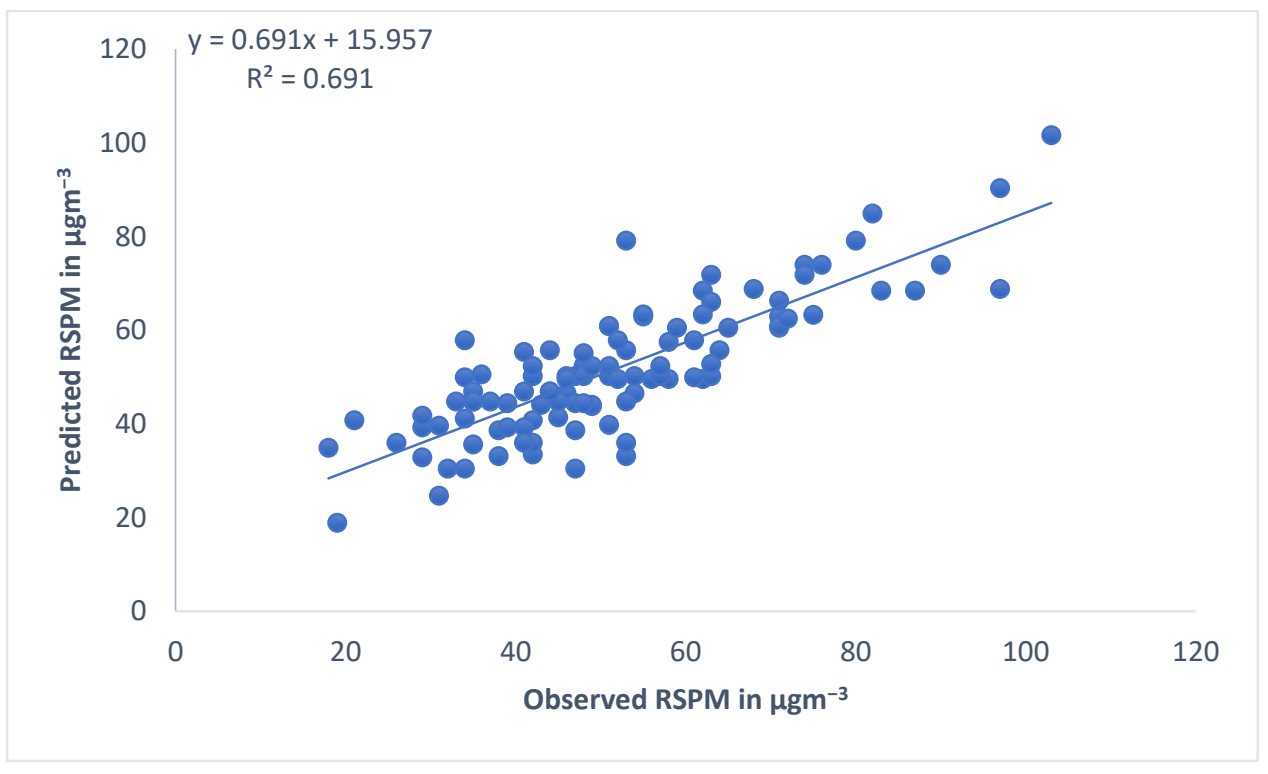

Fig. 13 Fitting results of summer RSPM data for March 2020 to February 2021

\section{Conclusions}

Computed and analysed statistics exposed that suspended particulate matter (SPM) and respirable suspended particulate matter (RSPM) were the major air pollutants at stations 2 and 3 respectively. However, the gaseous pollutants were well within the permissible limit at all locations. From the AQI values, it was found that there was unhealthy for sensitive group 
at two locations and moderate air pollution at remaining all four locations in conformity with the SPM and RSPM levels. It was also observed that the particulate emissions levels were relatively high during winter in comparison to monsoon and summer. To keep the SPM and RSPM concentrations within an acceptable level, it is suggested that for old diesel vehicles there is a need of invention of development of portable attachment kit at the outlet of exhaust (at the source of generation) for trapping of soot particles. Much research has been focused on emissions of Indian air pollution in major urban cities and industrial clusters. Also, there is a lack of adequate research on the degree of pollution concentrations in medium-scale cities, which is likely to increase in the near future. Apart from this, more research required on trees having high dust trapping efficiency and are to be grown alongside the roads and water is to be sprinkled continuously at the source of generation of particulate matter immediately. Also, there is a need of awareness in education of pollutant from primary to graduation level about the harmful effects of air pollution.

A multivariate linear regression equation was developed between RSPM and various gaseous pollutants considering meteorological parameters. It has been found that apparent seasonal differences in RSPM concentrations were found, with $\mathrm{R}^{2}$ values of $0.717,0.691,0.64$ and 0.60 for model utilising the data for winter, summer, annual and monsoon seasons respectively. The results of the regression models using winter data was superior to those that used in summer and monsoon data. From the study it has been confirmed that the main factor affecting the prediction validity was seasonal variations. As a precaution, the air pollution forecasting is the basis for effective pollution control measures, and accurate air pollution forecasting has become an important task. An admirable air pollution prediction approach can provide warning to user for avoiding too much polluted air inhalation. Finally, we aim to provide guidance to policy makers on how to reduce pollution exposure and thus provide health benefits to city residents.

\section{Acknowledgement}

Authors thanks to Dr A P Bodkhe, Principal, Dr P S Pajgade, and Head of Civil Engineering Department for their corporation and permission to carry out the laboratory work in the institute. We are also thankful to the director, Maharashtra Pollution Control Board Mumbai for providing required know how. I am also thankful to the Librarian from our institute, VNIT Nagpur and IIT Mumbai for permitting me to collect the required literature review. 


\section{References}

[1] Kunwar P. Singh, Shikha Gupta et al., "Linear and nonlinear modelling approaches for urban Air Quality Prediction", Science of the Total Environment 426, (2012), pp. 244-255

[2] Logan WPD, "Mortality in the London fog incident”, Lancet (1953);1:336-8.

[3] Nemery B, Hoet PHM, Nemmar A, "The Meuse Valley fog of 1930: an air pollution disaster”, Lancet (2001);357:704-8. Orr Mark JL.

[4] Bell M, Davis DL, "Reassessment of the lethal London fog of 1952: novel indicators of acute and chronic consequences of acute exposure to air pollution", Environ Health Perspect (2001);109:389-94.

[5] A hand book of Engineers Joint Council-USA, (1998).

[6] Dharpal $S V$, Ingole $N W$ et al., "Advances in Air Pollution its Monitoring and Remedial Measures - A Review", International Engineering Journal for research and development, Volume 4 Issue 4 (2020).

[7] $\quad C P C B$, "Guidelines for ambient air quality monitoring”, CPCB Publication No. B29016/20/90/PCI/L; (1998).

[8] Cimorelli AJ, Perry SG, Venkatram A, Weil J, Paine R, Wilson RB, et al., (2005), “AERMOD: a dispersion model for industrial source applications", Part I: general model formulation and boundary layer characterization. J Appl Meteorol (2005),44:682-93. 
[9] Bhaskar BV, Rajasekhar RVJ, Muthusubramaian P, Kesarkar AP, "Measurement and modeling of respirable particulate (PM10) and lead pollution over Madurai, India”, Air Qual Atmos Health; (2008), 1:45-55.

[10] EPA. "Guideline on air quality models (revised)", Research Triangle Park: NC: US Environmental Protection Agency; (2005), pp. 40 CFR 51.

[11] Kesarkar AP, Dalvi M, Kaginlkar A, Ojha A. "Coupling of the weather research and forecasting model with AERMOD for pollutant dispersion modelling”, A case study for PM10 dispersion over Pune, India. Atmos Environ (2007);41:1976-88.

[12] Collett RS, Oduyemi K., "Air quality modeling: a technical review of mathematical approaches", Meteorol Appl, (1997);4:235-46.

[13] Shi JP, Harrison RM., “ Regression modelling of hourly NOX and NO2 concentrations in urban air in London”, Atmos Environ (1997); 31:4081-94.

[14] Ziomas IC, Melas D, Zerefos CS, Bais AF, Paliatsos AG. Forecasting peak pollutant levels from meteorological variables. Atmos Environ (1995); 29:3703-11.

[15] Shi JP, Harrison RM. "Regression modelling of hourly NOX and NO2 concentrations in urban air in London”, Atmos Environ (1997); 31:4081-94.

[16] Dharpal $S V$, Ingole $N W$ et al., "Assessment of impact of thermal power station on air quality of Amravati city”, ICSTSD. (2016), pp37-41.

[17] Dr Bhola Ram Gurjar, "Air Pollution in India: Major Issues and Challenges", Teri, the energy \& research institute, India (2021).

[18] Rao C S, (1993), “Environmental Pollution control”, Wiley Eastern Ltd, New Delhi.

[19] Panda B.K. and Panda C.R., " Estimation of ambient air quality status in Kalinga Nagar industrial complex in the district of Jajpur of Odisha", International Journal of Environmental Sciences, Vol. 3, No 2, (2012), pp 767-775.

[20] EPA, 1999, “Air Quality Index Reporting; final Rule”, Federal Register, Part III, 40 CFR Part 58. 
[21] Sahu JN, Acharya J, Meikap BC. Response surface modeling and optimization of chromium (VI) removal from aqueous solution using tamarind wood activated carbon in batch process. J Hazard Mater (2009);172:818-25.

[22] Singh KP, Basant N, Malik A, Jain G., "Modeling the performance of up-flow anaerobic sludge blanket" reactor-based wastewater treatment plant using linear and nonlinear approaches - a case study. Anal Chim Acta (2010);658:1-11.

[23] Rui Zhao, Xinxin Gu et al., "Short period PM2.5 prediction based on multivariate linear regression model", Plos One, (2018), pp 1-15. 